corpuscles between Nov. 12th and 13th, corresponding to the first of these occasions. Corresponding to the second there FIG. 10.

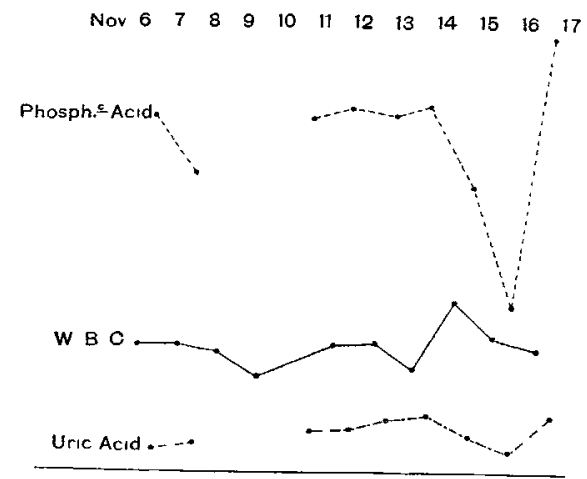

is no confirmatory evidence, seeing that no differential count was made either on Nov. 14th or 15th. (Table X.)

TABLE X.-Case 10.

\begin{tabular}{|c|c|c|c|c|c|c|c|c|c|c|}
\hline \multirow{3}{*}{ Date. } & \multirow{3}{*}{ 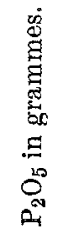 } & \multirow{3}{*}{ 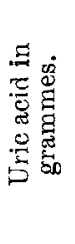 } & \multirow{3}{*}{$\begin{array}{l}0 \\
0 \\
0 \\
3\end{array}$} & \multirow{3}{*}{ 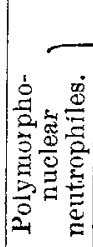 } & \multicolumn{5}{|c|}{ Differential counts. } & \multirow{3}{*}{ 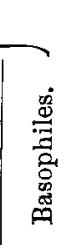 } \\
\hline & & & & & \multicolumn{2}{|c|}{$\begin{array}{c}\text { Lympho- } \\
\text { cytes. }\end{array}$} & \multirow{2}{*}{ 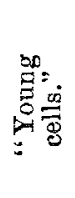 } & \multirow{2}{*}{ 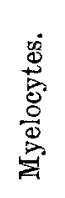 } & \multirow{2}{*}{ 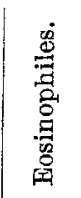 } & \\
\hline & & & & & 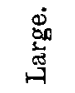 & 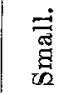 & & & & \\
\hline & & & & $\begin{array}{c}\text { Per } \\
\text { cent. }\end{array}$ & $\begin{array}{c}\text { Per } \\
\text { cent. }\end{array}$ & & $\begin{array}{c}\text { Per } \\
\text { cent. }\end{array}$ & & $\begin{array}{c}\text { Per } \\
\text { cent. }\end{array}$ & cent. \\
\hline ov. 6 th & 2.43 & & 8700 & 65.74 & $6 \cdot 06$ & $22 \cdot 95$ & $1 \cdot 80$ & 0.16 & $2 \cdot 78$ & 0.49 \\
\hline $7 \mathrm{th}$ & $2 \cdot 43$ & & 8830 & 54.96 & $6 \cdot 2$ & $28 \cdot 89$ & $5 \cdot 38$ & 0.0 & 3.96 & 0.56 \\
\hline " 8th & $2 \cdot 03$ & 0.21 & 8150 & - & - & - & - & - & - & - \\
\hline 9 th & - & - & 6550 & 6391 & $5 \cdot 15$ & $25 \cdot 15$ & $2 \cdot 06$ & 0.21 & 3.29 & 0.21 \\
\hline., 10 th & $2 \cdot 41$ & 0.29 & - & - & - & - & - & - & - & - \\
\hline & 2.48 & 0.30 & 8700 & 66.62 & 5.07 & $22 \cdot 76$ & $2 \cdot 15$ & 0.0 & $2 \cdot 77$ & 0.61 \\
\hline & $2 \cdot 42$ & $0 \cdot 35$ & 8820 & $64 \cdot 64$ & $4 \cdot 70$ & 2473 & $2 \cdot 73$ & 0.0 & $2 \cdot 88$ & $0 \cdot 30$ \\
\hline & $2 \cdot 50$ & $0 \cdot 39$ & 7020 & $62 \cdot 37$ & $5 \cdot 30$ & $26 \cdot 67$ & $2 \cdot 47$ & $0 \cdot 0$ & $2 \cdot 82$ & 0.35 \\
\hline & 1.94 & 0.24 & L1450 & - & - & - & - & - & - & - \\
\hline & $1 \cdot 12$ & $0 \cdot 15$ & 9050 & - & - & - & - & - & - & - \\
\hline & $2 \cdot 94$ & $0 \cdot 36$ & 8360 & $6 \hat{6} \cdot 36$ & 3.69 & $24 \cdot 58$ & $2 \cdot 40$ & 0.0 & $2 \cdot 58$ & 0.36 \\
\hline & & & - & - & - & - & - & - & - & - \\
\hline
\end{tabular}

CASE 11. - The patient was a female, aged 42 years. She was suffering probably from a new growth of the mediastinum. She died on June 22nd. In this case there are three

FIG. 11.

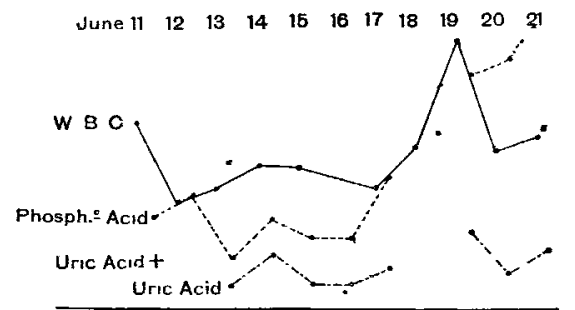

The mark + represents a reading of phosphoric acid.

corresponding rises in the phosphoric acid and uric acid curves following respectively three falls in the white blood corpuscle curve. There is, corresponding to these three occasions, confirmatory evidence of increased destruction of the white blood corpuscles between June 11th and 12th, 14th and 15th, and finally between the 19th and 20th. (Table XI.)

To Dr. Eustace Smith and to my colleagues at the City of London Hospital for Diseases of the Chest, Victoria Park, Dr. G. A. Heron, Dr. E. O. Beale, Dr. H. Sainsbury, Dr.
TABLE XI._Case 11.

\begin{tabular}{|c|c|c|c|c|c|c|c|c|c|}
\hline \multirow{3}{*}{ Date. } & \multirow{3}{*}{ 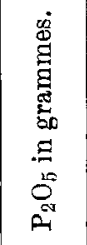 } & \multirow{3}{*}{ 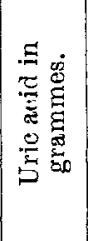 } & \multirow{3}{*}{$\begin{array}{l}0 \\
0 \\
0\end{array}$} & \multirow{3}{*}{ 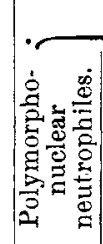 } & \multicolumn{5}{|c|}{ Differential counts. } \\
\hline & & & & & \multicolumn{2}{|c|}{$\begin{array}{l}\text { Lympho- } \\
\text { cytes. }\end{array}$} & \multirow{2}{*}{ 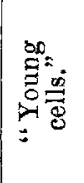 } & \multirow{2}{*}{ 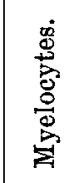 } & \multirow{2}{*}{ 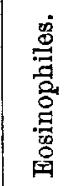 } \\
\hline & & & & & 离 & 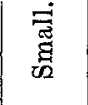 & & & \\
\hline & & & 12700 & $\begin{array}{c}\text { Per } \\
\text { cent. } \\
51 \cdot 97\end{array}$ & $\begin{array}{c}\text { Per } \\
\text { cent. } \\
11 \cdot 21\end{array}$ & $\begin{array}{c}\text { Per } \\
\text { cent. } \\
31 \cdot 43\end{array}$ & $\begin{array}{c}\text { Per } \\
\text { cent. } \\
0.79\end{array}$ & $\begin{array}{c}\text { Per } \\
\text { cent. }\end{array}$ & Per \\
\hline 12 th & 0.64 & 0.27 & 7300 & $58 \cdot 81$ & $7 \cdot 05$ & $30 \cdot 79$ & $1 \cdot 48$ & 0.0 & $\begin{array}{l}4.46 \\
1 \cdot 85\end{array}$ \\
\hline "13th & 0.79 & - & 8300 & $54 \cdot 24$ & 5.59 & $34 \cdot 06$ & $I \cdot 35$ & 0.0 & $4 \cdot 74$ \\
\hline, 14th & & 0.38 & 9900 & $55 \cdot 89$ & $11 \cdot 77$ & $26 \cdot 36$ & $2: 81$ & $0 \cdot 0$ & $3 \cdot 15$ \\
\hline " 15th & & & 9760 & $52 \cdot 04$ & $16 \cdot 83$ & $23 \cdot 97$ & $2 \cdot 89$ & $0 \cdot 17$ & $4 \cdot 08$ \\
\hline ", 16th & $\begin{array}{l}\text { (mean } \\
\text { of two } \\
\text { days) }\end{array}$ & $\begin{array}{l}\text { (mean } \\
\text { of two } \\
\text { days) }\end{array}$ & - & - & - & - & - & - & - \\
\hline " 17th & $\mid \begin{array}{c}0.49 \\
\text { mean } \\
\text { of two } \\
\text { days })\end{array}$ & $\mid \begin{array}{c}0 \cdot 17 \\
\text { mean } \\
\text { of two } \\
\text { days) }\end{array}$ & 8160 & 64.24 & $4 \cdot 23$ & $24 \cdot 40$ & $1 \cdot 69$ & 0.34 & $5 \cdot 08$ \\
\hline & 0.93 & $\begin{array}{l}0.29 \\
-\end{array}$ & 11050 & $67 \cdot 35$ & $5 \cdot 33$ & $25 \cdot 27$ & $\cdot 15$ & & 1.88 \\
\hline , 19th & & & 18300 & $68 \cdot 12$ & 1207 & $14 \cdot 97$ & $3 \cdot 22$ & $0 \cdot 16$ & 1.45 \\
\hline,$\quad 20 t h$ & $\begin{array}{l}1.05 \\
1.78\end{array}$ & $\begin{array}{l}0.04 \\
0.24\end{array}$ & 10700 & $70 \cdot 33$ & $12 \cdot 12$ & 1180 & $3 \cdot 82$ & $1 \cdot 27$ & 0.48 \\
\hline$\leadsto 21 s t$ & 1.7 & 0.24 & 11600 & $69 \cdot 32$ & $10 \cdot 41$ & $15 \cdot 72$ & $2 \cdot 65$ & $1 \cdot 13$ & 0.76 \\
\hline,,$\quad 22 n d$ & 211 & 0.59 & - & - & - & - & - & - & - \\
\hline
\end{tabular}

T. Glover Lyon, and Sir Hugh Beevor, I am indebted for permission to use the results obtained from cases under their care.

Upper Berkeley-street, $W$.

\section{A FORM OF REMOVEABLE DEEP SUTURE.}

BY F. R. S. MILTON, M.R.C.S. ENG., L.R.C.P. LOND., PROFESSOR OF CLINICAL SURGERY AT THE MEDICAL SOHOOL, CATRO; SURGEON TO, AND GURGEON IN CHARGE OF GYNACOLOGICAL WARDS AT, THE KASR-EI-AINI HOSPITAL, CAIRO.

ALTHOUGH an aseptic buried suture should remain buried and never be heard of further, still it does sometimes happen that such a suture will, after a time, make its presence known by causing the formation of a pustule to be followed by a sinus which will not heal until the offending stitch has been removed. This may happen after the completely aseptic healing of the original wound and even after every precaution has been taken in the preparation of the suture material. This reappearance of the suture is always a cause of annoyance to the patient and of heart-searching to the surgeon and, if a continuous suture has been used, as for instance, in the peritoneal suture after abdominal section, may necessitate the performance of an operation involving the opening up of the whole original wound. In order to get over this difficulty it is necessary to devise some form of suturing in which the deep suture, although practically buried, may still be removed at any period after the healing of the wound. Again, after many operations, such as those involving suturing at the bottom of cavities, such as in the vagina for vesico-vaginal fistulæ or in colporrhaphy, the patient has to undergo what may cause her almost more suffering than the original operation when the time comes for removing the stitches; and here again the use of an easily removeable suture would be of immense advantage both to the surgeon and to the patient.

It is evident that to be capable of removal at a period subsequent to complete inclosure in a healed wound, any suture of more than a single point must be a continuous one and the form of continuous suture most easily removed by a single application of force would seem to be that which is commonly known as the ordinary machine chain stitch and in order to make use of this it is only necessary to employ a form of needle which will take the entering and returning thread through the same hole. This, then, was the first form 
of stitch which I experimented with. In working this out on inanimate objects it answered perfectly well, but when it came to applying it to the living subject it was found that during the process of healing in the wound the chain got, as it were, fouled by the uniting tissue and the stitch would not pull out easily. Being dissatisfied with this I then tried the other form of sewing-machine or "lock" stitch, and this was found quite satisfactory and perfectly easy of removal provided certain points in its application were attended to.

In the ordinary sewing-machine the efficiency and neatness of the stitching depend upon preserving the ratio between the tensions of the two threads employed. If the tension is properly regulated the interlocking of the threads will take place in the substance of the material under suture, whereas if the tension of one of the threads be greater than that of the other the interlocking of the threads will take place on the surface of the material and on the side of the thread with the highest tensic $n$. By using two threads with different pliability in surgical suturing the same effect can be produced as would be caused by extreme difference in the tension in machining; thus, if one thread be of silk and the other of, say, stiff steel wire it is obvious that instead of the threads interlocking in the substance of the material they will hardly interlock at all, but the more pliable silk will simply pass round the stiff wire and the turns will all be on the side of the material to which the wire is applied, and, further, it will be found that on pulling the wire this can be easily withdrawn and in consequence the silk, having lost its support, can also be withdrawn with the slightest pull.

The method of introducing the suture is of the simplest. All that is required is a mounted needle with an eye near the point; through this is threaded a long piece of silk. This forms the primary thread; the secondary thread is best formed by a stout piece of silkworm-gut which is sufficiently rigid to avoid kinking and being drawn into the sutured tissue. Supposing the peritoneum is to be sutured after a laparotomy the procedure will be as follows:- The two layers of the peritoneum which are to be sewn together are defined the mounted needle, threaded, with the long end of the thread on the left hand or upper side of the ntedle when held as it will be when piercing the tissue, is passed from the operator through both layers of the peritoneum, beginning at the lower angle of the wound. The needle is then withdrawn, leaving a loop of silk protruding through the layers of peritoneum on the side of the assistant; through this loop the assistant passes the end of the silkworm-gut, from below upwards, and the loop is withdrawn flush with the assistant's side of the united flaps. The needle, not having been unthreaded, is again thrust through the flaps for the second stitch and again withdrawn, leaving a loop as in the first instance; the silkworm-gut is threaded through this second loop and the process is repeated till the whole of the flaps are united these being held together by a series of silk loops, the primary thread, held in position by the secondary thread of silkworm-gut passing through the loops on the assistant's side. The needle is next unthreaded, leaving a fairly long end to the silk. There will be now on the face of the wound, on the side of the surgeon, the two ends of silk, one entering the peritoneal flaps at the lower end of the wound and the other leaving the peritoneum at the upper end, and on the side of the assistant the silkworm-gut thread passing through the silk loops and also with long ends, one at the lower end of the wound and the other at the npper end. The silkworm-gut thread should now be put on the stretch and pulled gently backwards and forwards to see that it is nowhere kinked and that it can be withdrawn. This having been done, the four ends, two silk and two silkworm-gut, are each in turn threaded on an ordinary needle and made to pierce the skin on its own side of the wound and are left thus whilst the wound in the abdominal wall is sutured in the ordinary way. This having been done the two lower ends of the peritoneal suture, being one of silk and the other of silkworm-gut, are then tied together and cut to a convenient length. The same is done with the two ends at the upper end of the wound and the process is complete.

When it is required to remove the deep stitch, which may be any time after the wound is healed, all that is required is to cut the lower united stitches on the silk side of the knot and the upper stitch on the gut side of the knot, or vice vers $\hat{a}$, and to pull out first the silkworm.gut stitch which will offer no resistance, and then the silk stitch which having lost its support can be pulled out with equal facility.
The suturing itself can be done quite as rapidly as the ordinary continued suture and the only point requiring special attention is not to pull the silk loops so tight that they drag the silkworm-gut thread into the stitch hole or on to the silk side of the wound.

The method is applicable to any form of buried suture which it may be desirable to remove after healing, except that if the suturing has to take a curve of more than about a sextant two or more separate silkworm gut threads will have to be used in following the curve; otherwice, if the one thread has to curve round too great a part of a circle it will be found to drag on the loops on an attempt at withdrawal and will not run.

There would appear to be no limit, in reason, to the time that the suture may be left in position without causing trouble, provided the part be kept aseptic; thus, in cases of radical cure of hernia I bave kept the stitches closing the ring in position for 15 days without any sign of suppuration or irritation and with no indication that such was likely to occur, and at the end of that time have removed the stitches without the slightest difficulty.

Up to the present I have employed the stitch in cases of laparotomy, in radical cure of hernia, in suprapubic cystotomy, for suturing the pleura in cases of abscess of the liver, and in colporrhaphy, and have found it to answer very well

Cairo.

\section{A CASE OF TYPHOID PANCREATITIS.}

By B. G. A. MOYNIHAN, M.S. LOND., F.R.C.S. ENG., SENIOR ASSISTANT SURGEON TO THE LEEDS GENERAL INFIRMARY; CONSULTING SURGEON TO THE SKIPTON HOSPITAL AND TO THE MIRFIELD MEMORIAL HOSPITAL.

Ix has been generally recognised, since Riedel in 1892 first drew attention to the fact, that chronic pancreatitis is not infrequently dependent upon the irritation of gall-stone disease. The constantly recurring attacks of cholangitis aroused by the passing of a stone down the cystic and common ducts, the impaction of a stone in the lower end of the common duct, and especially its lodgment in the ampulla of Vater, may all be the determining causes of a chronic inflammation of the pancreas.

Among causes other than gall-stones which are capable of originating an acute inflammation of any part of the bile passages typhoid fever, as shown by Murchison, Keen, and many others, takes a prominent place. The bacillus typhosus may be found in the bile for many months or even years after an attack of typhoid fever. In one case a pure culture of the organism was obtained from the bile in the gall-bladder after seven years. Since the common bile-duct and the duct of the pancreas have a common opening into the duodenum at the ampulla of Vater it is not difficult to understand how an ascending infection attacking the bile passages may also affect the canal of Wirsung. In the following case there was a condition of typhoid pancreatitis associated with an infection of the gall-bladder by the bacillus typhosus.

The patient, a boy, aged 13 years, who was s $\epsilon$ nt to me by Dr. W. A. H. Waite of Leeds, was admitted to the Leeds General Infirmary on March 2nd, 1903. The history of the case was that he had been in his usual good health up to September, 1901. In that month he had typhoid fever, from which he made a slow but satisfactory recovery. At frequent intervals since his convalescence he complained of attacks of pain in the upper part of the abdomen. When asked to point out the seat of the most severe pain he laid his hand across the epigastrium. The pain on several occasions had lasted for three or four hours and had been accompanied by feelings of nausea and, though rarely, by vomiting. In November, 1902, for the first time such an attack was followed by jaundice which lasted for several days and then gradually cleared away. Almost every week since November similar attacks of pain, varying in intensity, had occurred and the jaundice had deepened slightly after each attack. The jaundice had never cleared away completely, though it had varied much in depth of tinge. There had never been any elevation of temperature when the pain had come and there had been neither shivering nor flushing. For the last three months the appetite had been poor and the boy had become considerably emaciated. 